\title{
Effects of acute cold exposure on plasma inflammatory and lipid biomarkers related to cardiovascular disease risk
}

\author{
Sarah L Ullevig*, Masataka Umeda, Eunhee Chung, Ana L Sesatty, Karina E Samsuhadi and Donovan L Fogt \\ Department of Kinesiology, Health, and Nutrition, The University of Texas at San Antonio, One UTSA Circle, San Antonio, TX, USA
}

\begin{abstract}
Purpose: Acute cold exposure (ACE) stimulates metabolism but data evaluating inflammatory and lipid biomarkers related to cardiovascular disease in response to $\mathrm{ACE}$ are lacking. Therefore, we investigated the relationship between $\mathrm{ACE}$ and inflammatory and lipid biomarkers.

Methods: Twenty subjects underwent 30 min of ACE with blood drawn: 1) pre-ACE (baseline), 2) at 30 min ACE, and 3) $2 \mathrm{~h}$ post-ACE. Plasma was analyzed for 10 cytokines (monocyte chemoattractant protein-1 (CCL2), interleukin (IL)-1ß, IL-2, IL-4, IL-6, IL-8, IL-10, granulocyte-macrophage colony stimulating factor (GM-CSF), tumor necrosis factor-alpha (TNF- $\alpha$ ), interferon-gamma (INF $\gamma$ )), 9 acute phase proteins (ferritin, fibrinogen, procalcitonin, serum amyloid A, serum amyloid P, tissue plasminogen, C-reactive protein, haptoglobin, $\alpha-2$-macroglobin), and 5 lipid biomarkers (triglycerides, nonesterified fatty acids (NEFA), low- and high-density lipoprotein (LDL, HDL), and total cholesterol). Heart rate, whole body oxygen consumption $\left(\mathrm{VO}_{2}\right)$, energy expenditure (EE), shivering sensations, and pain were measured prior and during ACE.
\end{abstract}

Results: ACE increased heart rate by $11 \%$, shivering sensations by 4 -fold, pain by 2 -fold, VO2 by $50 \%$, and EE by $52 \%$. IL- $1 \beta$ increased after 30 min ACE by $24 \%$ $(p=0.048)$ and $2 \mathrm{~h}$ post ACE by 65\% ( $p=0.01)$. Alpha-2-macroglobin increased after $30 \mathrm{~min}$ ACE by $16 \%(p=0.005)$ and returned to baseline levels $2 \mathrm{~h}$ post-ACE. HDL increased at $2 \mathrm{~h}$ post-ACE by $15 \%$ ( $p=0.034)$. Sex differences were noted between IL-2, IL-6, IL-8, ferritin, $\alpha-2$-macroglobin and HDL.

Conclusions: These findings indicate ACE increases EE and modifies inflammation, the acute phase response, and lipid metabolism. Long-term risk of CVD needs further exploration to assess the risks or benefits of ACE. Future studies with diverse subjects varying in age and body composition and studies aimed to determine the effectiveness of $\mathrm{ACE}$ as compared to diet and exercise are warranted.

\begin{abstract}
Abbreviations: ACE : Acute cold exposure, ACTH: Adrenocorticotropic hormone, ANOVA: Analysis of variance, BMI: Body mass index, BW: Body weight, CCL2: Chemokine (C-C motif) ligand 2 or known as MCP-1 (monocyte chemoattractant protein-1), CRP: C-reactive protein, CVD: Cardiovascular disease, EE: Energy expenditure, GM-CSF: Granulocyte-macrophage colony stimulating factor, HDL: High-density lipoprotein, IL: Interleukin, INF- $\gamma$ : Interferon gamma, LDL: Low-density lipoprotein, NEFA: Nonesterified fatty acids, SPSS: Statistical Package for the Social Sciences, TC: Total cholesterol, TG: Triglyceride, TNF- $\alpha$ : Tumor necrosis factor alpha, $\mathrm{VO}_{2}$ : Whole body oxygen consumption.
\end{abstract}

\section{Introduction}

Cardiovascular diseases (CVD) are the leading causes of death in US and the world [1], and approximately 610,000 individuals die of CVD in the US each year [2]. Past research has shown that the underlying causes of most cases of CVD are chronic inflammation and elevated blood lipids, and both inflammatory cytokines and lipid mediators are used as biomarkers to assess CVD risks [3]. It is well accepted that positive lifestyle modifications, such as regular engagement in physical activity and high diet quality, leads to health benefits, including improvement in CVD-associated lipid and inflammatory biomarkers. Unfortunately, epidemiological research has repeatedly shown that prevalence of enough physical activity and adequate nutrition among US adults are still far from satisfactory [4,5], suggesting a need of developing other approaches that may serve as an alternative option to reduce the risk of CVD. A potential approach that may warrant further investigation is a systemic exposure to cold stimulus due its potential beneficial physiological and metabolic effects [6,7].

The effects of cold environment on human physiology have been investigated using an acute cold exposure (ACE) paradigm, where study participants were typically exposed to cold environment in a laboratory. A commonly used approach in cold exposure research is to utilize a temperature-controlled room $\left(4-15^{\circ} \mathrm{C}\right)$ for $30-120$ minutes [7-12]. Alternatively, a liquid-conditioned tube suit perfused with $8^{\circ} \mathrm{C}$ water for 180 minutes was utilized [6]. Using these experimental approaches, research shows that ACE induces substantial changes in a variety of physiological variables. Some physiological changes are characterized by increases in heat production, oxygen consumption, and energy expenditure, as well as decrease in skin temperature [79], whereas other physiological changes include those similar to stress responses, such as increases in epinephrine, norepinephrine, adrenocorticotropic hormone (ACTH), and cortisol [9-12]. Together, data from past research indicate that ACE is a potent environmental stimulus to induce substantial changes in human physiology, some of which resemble metabolic responses to increasing activity levels

${ }^{*}$ Correspondence to: Sarah L Ullevig, Department of Kinesiology, Health, and Nutrition, The University of Texas at San Antonio, One UTSA Circle, San Antonio, TX, USA, E-mail: sarah.ullevig@utsa.edu

Key words: cold exposure, shivering, cytokines, acute phase proteins, biomarkers

Received: December 19, 2018; Accepted: December 28, 2018; Published: December 31, 2018 
(e.g., increased heat production, oxygen consumption, and energy expenditure). Thus, ACE may result in favorable changes in CVD risk profiles, as well as increases in metabolic rates.

Currently, very little is known whether exposure to cold stimulus brings about positive effects on CVD risks. Cold exposure may depress the immune system and led to increased upper respiratory tract infection or "colds" [13] but research is conflicting [14]. Colder regions and colder winter are generally associated with increased prevalence and severity of CVD, including hypertension, heart attack, and stroke [15] suggesting potentially adverse effects of cold environment on CVD risks. Rodent and equine studies found short and long-term cold exposure increased blood pressure, inflammatory and lipid biomarkers in the blood, and atherosclerosis lesion development $[16,17]$. Conversely, cold exposure in mice increased brown adipose tissue activity that decreased triglyceride blood concentrations and improved insulin resistance [18] as seen in humans [6]. Human laboratory studies have been conducted examining the effects of ACE on CVD biomarkers. The lab-based studies have measured blood cell counts and a limited number of cytokines in response to ACE $[14,17,19]$ without a consensus as to the effects. Furthermore, the lab studies have failed to address a wide array of inflammatory cytokines, acute phase proteins, and lipid mediators to provide a comprehensive view of CVD risk profiles.

CVD risk is associated with an imbalance between inflammatory cytokines and anti-inflammatory cytokines, hyperlipidemia, and indicators of stress. Blood levels of the lipid biomarkers, such as total cholesterol, low-density lipoprotein (LDL) cholesterol, triglycerides and non-esterified fatty acids (NEFA) are associated with increased CVD risk and are used in the diagnosis of metabolic syndrome [20]. Inflammatory cytokines associated with increased CVD risk include interleukin 1-beta (IL-1 $\beta$ ), monocyte chemoattractant protein-1 (MCP-1), IL-4, IL-6, IL-8, granulocyte macrophage-colony stimulating factor (GM-CSF), interferon-gamma (INF- $\gamma$ ), and tumor necrosis factor-alpha (TNF- $\alpha$ ) $[3,20,21]$. High-density lipoprotein (HDL) and anti-inflammatory cytokines IL-2 and IL-10 are associated with a reduced risk of CVD $[20,22,23]$. In addition, changes in expression of acute phase proteins can be used to assess tissue damage after a CVD event or physiological stress. Chronic inflammation and CVD disease risk has been associated with alteration in the production of particular acute phase proteins including C-reactive protein, ferritin, fibrinogen, procalcitonin, serum Amyloid A, serum Amyloid P, tissue plasminogen, a-2-macroglobin, and haptoglobin [3,20,24-32]. Therefore, to fill the gap in the relevant literature, the present study aimed to examine the effects of ACE on a comprehensive panel of plasma inflammatory, lipid biomarkers and acute phase proteins related to CVD risk.

\section{Materials and methods}

\section{Subjects}

This study was approved by the Committee for the Protection of Human Subjects in Research of the University of Texas at San Antonio. All data were collected in the Exercise Biochemistry and Metabolism Laboratory, Department of Kinesiology, Health, and Nutrition, the University of Texas at San Antonio. Daily laboratory temperatures range from $22-24^{\circ} \mathrm{C}$. Average outdoor temperatures ranged from $18-26^{\circ} \mathrm{C}$ and participants were not cold acclimated. Body weight and composition were assessed by bioelectrical impedance (Tanita). Twenty individuals gave consent, self-reported as not having thyroid hormone-related disease or to be taking medications affecting metabolism, and then completed the protocol described below. Females were not screened for the phase of the menstrual cycle.
The sample size was estimated based on literature review of relevant research and power analysis. Past studies documenting the effects of ACE on physiological variables were typically conducted with a small number of healthy adults ( $n=5-16)$ [6-12] suggesting that the effects of ACE on outcome measures are likely to be large. Therefore, a power analysis was performed, with an alpha $=0.05$, a power $=0.80$, and a large effect size $(\mathrm{f}=0.40)$ [33], and results from the power analysis indicated that 12 individuals would be needed for this study to detect significant effects of ACE on the outcome measures. To account for potential missing data due to subjects' termination of the study protocol and technical issues during the study protocol, a total of 20 individuals participated in this study.

\section{Protocol}

Subjects were asked to fast for $10 \mathrm{~h}$, sleep at least $6 \mathrm{~h}$, refrain from caffeine, alcohol, dietary supplements, medications, and any activity (e.g., exercise) above that required for basic grooming and activities of daily living for $12 \mathrm{~h}$ prior to their testing session, minimizing intersubject energy expenditure (EE) variability. Prior to testing, subjects voided their bladders and then sat in a comfortable chair with controlled/ minimized visual or auditory stimulation for $10 \mathrm{~min}$ followed by instrumentation for the $3.3 \mathrm{~h}$ protocol of standard indirect calorimetry. Non-invasive EE estimates were made using indirect calorimetric estimations of human energy utilization using the thermal equivalents of oxygen for the non-protein respiratory quotient (ParvoMedics Inc, Sandy UT). Subjects' movement was kept at a minimum throughout the entire $3.3 \mathrm{~h}$ protocol ( 40 minutes baseline, $30 \mathrm{~min}$ ACE, and then $2 \mathrm{~h}$ post with extra time for transitions) to control for extraneous body EE. All subjects watched the same non-action movie video with external noise-cancelling headphones to help control stimuli throughout each phase of the protocol, minimizing the possible effects of extraneous stimuli from lab personnel, doors closing, etc. Subjects were seated for the entire protocol. Subjects' tympanic temperature was assessed (ThermoScan 6021 Ear thermometer Braun; Kaz; Hudson, NY, USA). Heart rate was assessed using a heart rate monitor (Polar RS800, Polar, Kempele, Finland).

\section{Pre-ACE}

First, subjects submerged their feet and lower legs (up to their knees) in water $\left(27^{\circ} \mathrm{C}\right)$ and soaked-towels $\left(27^{\circ} \mathrm{C}\right)$ were draped on their thighs, shoulders, arms, and the back of their neck to mimic the prep used during the subsequent cold-exposure phase. Water $\left(27^{\circ} \mathrm{C}\right)$ was poured on the subject every minute to maintain temperature during the pre-cold phase. Second, the movie was started, and subjects sat still for the entire $40 \mathrm{~min}$ pre-cold period.

\section{ACE}

After 40 min of pre-cold data collection, investigators quickly ( 30 sec) had subjects move their legs from the $27^{\circ} \mathrm{C}$ tub into a $7^{\circ} \mathrm{C}$ water bath. The $27^{\circ} \mathrm{C}$ towels were replaced by ice water-soaked towels $\left(7^{\circ} \mathrm{C}\right)$. A large high-power air fan was positioned towards the subjects. All other instrumentation remained in place during the transition. Water $\left(7^{\circ} \mathrm{C}\right)$ was poured on the subjects every minute to maintain temperature during the cold phase. Subjects provided a finger indication of shivering onset and indicated shivering intensity using a Likert-style scale (1=light to $10=$ severe) when promoted every $5 \mathrm{~min}$ throughout the $30 \mathrm{~min}$ cold exposure period to report self-reported shivering sensations. Subjects' perceived discomfort was assessed every $5 \mathrm{~min}$ and ranged from zero being no discomfort to ten being extreme discomfort to report pain due to ACE. Thirty minutes acute cold exposure has been reported in 
the literature [11] and was found to increase resting metabolic rate in previous studies conducted in our lab. Thirty minutes was also chosen to simulate a 30-minute moderate-intensity exercise session that is for physical activity recommendation for the adults.

\section{Post-ACE}

After the 30 min cold exposure, investigators quickly had subjects lift their legs from the cold tub into the $27^{\circ} \mathrm{C}$ water bath. Cold towels were replaced with $27^{\circ} \mathrm{C}$ towels and the air fan turned off. Subjects sat at quiet rest for $2 \mathrm{~h}$ of continued data collection as described above.

\section{Blood and Plasma Collection}

Fifteen to thirty milliliters of blood were collected by venipuncture at three-time points: 1) pre-ACE (baseline), 2) at $30 \mathrm{~min}$ ACE, and 3) $2 \mathrm{~h}$ post-ACE. Blood was collected in tubes containing ethylenediaminetetraacetic acid (EDTA, $24 \mathrm{mg} \cdot \mathrm{ml}^{-1}, \mathrm{pH}$ 7.4) and plasma recovered following centrifugation (15 $\mathrm{min}$ at $1,000 \mathrm{x} \mathrm{g}$ ) and stored at $-80^{\circ} \mathrm{C}$ until subsequent analysis.

\section{Cardiovascular disease biomarkers}

Inflammatory cytokines: Ten cytokines associated with cardiovascular disease were measured. Enzyme-linked immune absorbent assay (ELISA) ready-to-go kits (eBiosciences, San Diego, CA) were used to measure interleukin 1beta (IL-1 $\beta$ ), and monocyte chemoattractant protein-1 (MCP-1, also known as CCL2) in plasma. The Human Cytokine 8-plex BioPlex Pro assay (Bio-Rad Laboratories, Hercules, CA) was used to measure IL-2, IL-4, IL-6, IL-8, IL-10, granulocyte macrophage-colony stimulating factor (GM-CSF), interferon-gamma (INF- $\gamma$ ), and tumor necrosis factor-alpha (TNF- $\alpha$ ) using the Bio-Plex protein array system (Luminex-based technology; Bio-Rad Laboratories, Hercules, CA).

Acute phase proteins: Acute phase proteins associated with cardiovascular disease risk were measured. C-reactive protein (CRP), alpha-2-macroglobin, haptoglobin, serum amyloid $\mathrm{P}$ were measured using the Human Acute Phase 4-plex Bioplex Pro assay (BioRad) and ferritin, fibrinogen, procalcitonin, serum amyloid $\mathrm{A}$, and tissue plasminogen activator were measured using the Human Acute Phase 5-plex Bioplex Pro assay (Bio-Rad Laboratories, Hercules, CA).

Lipid biomarkers: Colorimetric assays (Wako Diagnostics, Richmond, VA) were used to measure total cholesterol (TC), lowdensity lipoprotein cholesterol (LDL), high-density lipoprotein cholesterol (HDL), triglycerides (TG) in plasma, and nonesterified fatty acids (NEFA).

\section{Statistical analysis}

The primary aim of this study was to examine the effects of ACE on inflammatory and lipid biomarkers related to cardiovascular disease risk. The sample size was estimated to achieve the primary aim, and cytokine, acute phase protein, lipid biomarker, and physiological data were analyzed with the data from 20 human subjects using repeated measures ANOVA, where the outcome measures were assessed at three time points (pre-ACE, $30 \mathrm{~min} \mathrm{ACE}$, and $2 \mathrm{~h}$ post-ACE). Additionally, sex differences in the outcome measures were examined as the preliminary analyses using 2 (sex: males and females) $\times 3$ (measurement times: pre-ACE, $30 \mathrm{~min}$ ACE, and $2 \mathrm{~h}$ post-ACE) mixedmodel ANOVA. Post hoc analyses were performed for these analyses using the Least Significant Difference method (SPSS statistical software, IBM) to determine significant differences. Study subject characteristics were analyzed using Student's t-test (SPSS statistical software, IBM). All data are presented as mean \pm SEM of 20 human subjects unless stated otherwise. Variables less than 20 resulted from missing participant data or undetectable results. Results were considered statistically significant at the $p<0.05$ level. The analyses with an entire sample were performed to test the primary aims of the study. However, due to sex differences in body composition (reported in Results section below), the analyses on sex differences in the outcome measures were performed to provide supplementary data of interest.

\section{Results}

\section{Subject characteristics and physiological parameters}

Twenty subjects, with 11 males and 9 females participated this study. Age and BMI were similar between males and females. However, height, weight, lean body mass, fat mass, \% body fat, and lean mass normalized to body weight (BW) were significantly different between males and females (Table 1). Physiological parameters measured at preACE (baseline) and at 30 min ACE are summarized in Table 2. Tympanic temperature decreased slightly from pre-cold to after $30 \mathrm{~min}$ of ACE (Table 1). However, as expected, heart rate $(p<0.05)$, self-reported shivering sensations $(p<0.001)$, perceived discomfort $(p<0.001), \mathrm{VO}_{2}$ $(p<0.001)$, and EE $(p<0.001)$ significantly increased after $30 \mathrm{~min}$ ACE than baseline (Table 2). Therefore, these data demonstrate that ACE in the present study resulted in similar metabolic responses to previous studies [34].

Since body composition is significantly different between males and females, sex differences were analyzed and reported in supplementary data (Supplementary Tables 1-4) and combined data are reported in Tables 2-5. As shown in supplementary table 1, there were no sex differences in physiological parameters in response to ACE, except females had significantly higher HR at baseline than males.

\section{Inflammatory Cytokines}

The levels of IL-1 $\beta$, a pro-inflammatory cytokine, significantly increased by $24 \%$ at $30 \mathrm{~min} \operatorname{ACE}(\mathrm{p}=0.048)$ and $65 \%$ at 2 h postACE $(\mathrm{p}=0.01)$ compared to baseline (Table 3$)$. The repeated measures

Table 1. Subject characteristics

\begin{tabular}{|c|c|c|c|}
\hline Variable & Males $(\mathbf{n}=\mathbf{1 1})$ & Females $(\mathbf{n}=\mathbf{9})$ & All $(\mathbf{n}=\mathbf{2 0})$ \\
\hline Age $(\mathrm{y})$ & $24.2 \pm 0.8$ & $23.6 \pm 0.9$ & $23.9 \pm 0.6$ \\
\hline Height $(\mathrm{cm})$ & $175.7 \pm 2.8$ & $164.7 \pm 3.0^{*}$ & $170.1 \pm 2.4$ \\
\hline BW $(\mathrm{kg})$ & $80 \pm 12$ & $67 \pm 12^{*}$ & $74 \pm 13$ \\
\hline BMI $\left(\mathrm{kg} / \mathrm{m}^{2}\right)$ & $26.1 \pm 1.1$ & $24.4 \pm 0.8$ & $25.4 \pm 0$ \\
\hline Lean Mass $(\mathrm{kg})$ & $69.7 \pm 4.1$ & $46.5 \pm 3.2^{*}$ & $59.7 \pm 4.1$ \\
\hline Fat Mass $(\mathrm{Kg})$ & $17.1 \pm 2.0$ & $11.5 \pm 1.5^{*}$ & $13.9 \pm 1.4$ \\
\hline \% Body Fat & $14.0 \pm 1.4$ & $26.5 \pm 1.5^{*}$ & $19.4 \pm 2.0$ \\
\hline Lean Mass/BW & $0.73 \pm 0.02$ & $0.86 \pm 0.01^{*}$ & $0.81 \pm 0.02$ \\
\hline
\end{tabular}

Values are expressed as mean $\pm \mathrm{SEM}$; BW, body weight; BMI, body mass index; " $p<0.05$, compared to males. $\mathrm{n}=8$ for male and $\mathrm{n}=6$ for female for lean mass, fat mass, and $\%$ Body fat

Table 2. Acute cold exposure measured physiological and self-reported parameters

\begin{tabular}{|l|c|c|c|}
\hline Variable & Baseline & 30 min ACE & n \\
\hline Heart Rate (beats $/ \mathrm{min})$ & $66.3 \pm 2.84$ & $73.9 \pm 3.17^{*}$ & 15 \\
\hline Temperature $\left({ }^{\circ} \mathrm{C}\right)$ & $36.8 \pm 0.09$ & $36.4 \pm 0.11^{*}$ & 20 \\
\hline $\mathrm{VO}_{2}(\mathrm{ml} / \mathrm{kg} / \mathrm{min})$ & $3.86 \pm 0.35$ & $5.78 \pm 0.28^{* *}$ & 18 \\
\hline $\mathrm{EE}(\mathrm{kcal} / \mathrm{min})$ & $1.38 \pm 0.08$ & $2.10 \pm 0.09^{* *}$ & 18 \\
\hline Shivering Sensations & $0.00 \pm 0.00$ & $4.05 \pm 0.48^{* *}$ & 19 \\
\hline Pain & $0.00 \pm 0.00$ & $1.95 \pm 0.59^{* *}$ & 19 \\
\hline
\end{tabular}

Values are expressed as mean \pm SEM. " $p<0.05,{ }^{* * *} p<0.001$ 
ANOVA revealed that several cytokines significantly changed in response to ACE when expressed as fold changes from baseline to treatment (Supplementary Figure 1). For example, IL-4 increased by $15 \%(\mathrm{p}=0.018)$ immediately after cold exposure and increased by $23 \%$ from baseline at $2 \mathrm{~h}$ post-ACE ( $\mathrm{p}=0.015$, Supplementary Figure 1). IL-2 and IL-10, anti-inflammatory cytokines, increased $22 \%(\mathrm{p}=0.025)$ and $35 \%(\mathrm{p}=0.024)$ respectively, after $2 \mathrm{~h}$ post-ACE (Supplementary Figure $1)$. However, no significant cold-induced change in the inflammatory cytokines IL-6, IL-8, CCL2, GM-CSF, and TNF- $\alpha$ compared to preACE values (Table 3 ). With further analysis by sex differences, the levels of IL-2, IL-4, and IL8 were significantly increased in males, but not in females (Supplementary Table 2).

\section{Acute phase proteins}

No change was observed at $30 \mathrm{~min}$ ACE from baseline measurements for ferritin, fibrinogen, procalcitonin, serum amyloid A, tissue plasminogen, CRP, and haptoglobin (Table 4). The levels of $\alpha-2$ macroglobulin increased $16 \%(\mathrm{p}=0.005)$ at $30 \mathrm{~min}$ ACE and decreased to pre-ACE levels at $2 \mathrm{~h}$ post-ACE (Table 4 and Supplementary Figure 1). These significant changes were seen in males, but not females (Supplementary Table 3). As expected, ferritin, an important protein for storing iron in the tissues, was significantly lower in females compared to males (Supplementary Table 3). Sex differences were present in fibrinogen levels after $30 \mathrm{~min}$ ACE compared to baseline, showing a greater increase in females as compared to males.

The repeated measures ANOVA of fold change revealed serum amyloid P increased by $9 \%(p=0.044)$ at $30 \mathrm{~min}$ ACE and decreased to pre-ACE levels at $2 \mathrm{~h}$ post-ACE. Although procalcitonin and CRP did not show a statistically significant difference, there was a trend for increased expression at $30 \mathrm{~min}$ ACE ( $p=0.089$ and $p=0.065$ respectively).

\section{Lipid biomarkers}

TC, LDL, TG, and NEFA did not change in response to ACE (Table 5). Interestingly, HDL cholesterol significantly increased at 2 $\mathrm{h}$ post ACE by $15 \%(p=0.006)$. The increase is largely seen in females (Supplementary Table 4). Females had significantly higher LDL at baseline than males (Supplementary Table 4), along with higher \% fat and fat mass (Table 1).

The repeated measures ANOVA of fold change revealed a significant increase in HDL at $30 \mathrm{~min}$ ACE by $8 \%(p=0.032)$ and increased an additional $5 \%(p=0.034)$ at $2 \mathrm{~h}$ post-ACE, for a total increase of $13 \%$ at $2 \mathrm{~h}$ compared to pre-ACE ( $p=0.002)$ (Supplementary Figure 1).

Table 3. Measured cytokines in plasma 1) pre-ACE (baseline), 2) after 30min of ACE, and 3) $2 \mathrm{~h}$ post-ACE

\begin{tabular}{|c|c|c|c|c|}
\hline $\begin{array}{c}\text { Cytokine (pg/ } \\
\text { mL) }\end{array}$ & Baseline & 30 min ACE & 2 h post ACE & n \\
\hline IL-1 $\beta$ & $18.5 \pm 4.33$ & $23.0 \pm 4.60^{* *}$ & $30.5 \pm 4.01^{\text {*** }}$ & 11 \\
\hline IL-2 & $5.11 \pm 0.380$ & $5.74 \pm 0.593$ & $6.16 \pm 0.663$ & 20 \\
\hline IL-4 & $1.28 \pm 0.079$ & $1.45 \pm 0.050$ & $1.59 \pm 0.151$ & 20 \\
\hline IL-6 & $6.71 \pm 0.230$ & $7.01 \pm 0.308$ & $7.87 \pm 0.623$ & 20 \\
\hline IL-8 & $6.58 \pm 0.391$ & $6.78 \pm 0.383$ & $7.04 \pm 0.607$ & 20 \\
\hline IL-10 & $6.33 \pm 0.353$ & $7.05 \pm 0.683$ & $8.48 \pm 1.05$ & 20 \\
\hline CCL2 & $116 \pm 16.5$ & $132 \pm 24.2$ & $138 \pm 27.7$ & 16 \\
\hline TNF $\alpha$ & $18.7 \pm 1.30$ & $18.4 \pm 1.45$ & $22.2 \pm 2.82$ & 20 \\
\hline GMCSF & $18.0 \pm 3.28$ & $14.5 \pm 1.79$ & $23.4 \pm 3.89$ & 12 \\
\hline
\end{tabular}

Values are expressed as mean concentration $\pm \mathrm{SEM} ;{ }^{*} p<0.05, * * p<0.01$ compared to baseline.
Table 4. Measured acute phase proteins in plasma 1) pre-ACE (baseline), 2) after 30min of $\mathrm{ACE}$, and 3) $2 \mathrm{~h}$ post-ACE

\begin{tabular}{|c|c|c|c|c|}
\hline Acute Phase Proteins & Baseline & $\mathbf{3 0}$ min ACE & 2 h post ACE & $\mathbf{n}$ \\
\hline Ferritin $(\mathrm{ng} / \mathrm{mL})$ & $19.3 \pm 3.55$ & $19.6 \pm 3.97$ & $19.4 \pm 3.91$ & 20 \\
\hline Fibrinogen $(\mathrm{mg} / \mathrm{dL})$ & $9.82 \pm 0.500$ & $10.0 \pm 0.647$ & $10.3 \pm 0.942$ & 20 \\
\hline Procalcitonin $(\mathrm{ng} / \mathrm{mL})$ & $0.512 \pm 0.076$ & $0.520 \pm 0.079$ & $0.476 \pm 0.056$ & 20 \\
\hline Serum Amyloid A (mg/L) & $0.364 \pm 0.051$ & $0.337 \pm 0.044$ & $0.361 \pm 0.048$ & 20 \\
\hline Tissue Plasminogen $(\mathrm{ng} / \mathrm{mL})$ & $1.38 \pm 0.124$ & $1.32 \pm 0.090$ & $1.30 \pm 0.093$ & 20 \\
\hline C-reactive protein $(\mathrm{mg} / \mathrm{L})$ & $0.048 \pm 0.016$ & $0.051 \pm 0.016$ & $0.049 \pm 0.016$ & 20 \\
\hline$\alpha-2$-macroglobin $(\mathrm{mg} / \mathrm{dL})$ & $127 \pm 7.57$ & $147 \pm 9.63^{* *}$ & $129 \pm 11.0$ & 20 \\
\hline Serum Amyloid $\mathrm{P}(\mathrm{mg} / \mathrm{dL})$ & $2.35 \pm 0.169$ & $2.46 \pm 0.176$ & $2.44 \pm 0.192$ & 20 \\
\hline Haptoglobin $(\mathrm{mg} / \mathrm{dL})$ & $26.3 \pm 5.54$ & $26.6 \pm 5.63$ & $26.8 \pm 4.99$ & 16 \\
\hline
\end{tabular}

Values are expressed as mean concentration $\pm \mathrm{SEM} ;{ }^{*} p<0.05,{ }^{*} p<0.01$

Table 5. Measured lipids in plasma 1) pre-ACE (baseline), 2) after 30min of ACE, and 3) $2 \mathrm{~h}$ post-ACE

\begin{tabular}{|l|l|l|l|l|}
\hline Lipid biomarkers & Baseline & $\mathbf{3 0}$ min ACE & 2 h Post ACE & n \\
\hline Triglycerides (mg/dL) & $57.4 \pm 7.39$ & $61.4 \pm 8.59$ & $65.6 \pm 11.2$ & 16 \\
\hline Free Fatty Acids (uM) & $417 \pm 68.6$ & $412 \pm 47.7$ & $437 \pm 54.0$ & 15 \\
\hline Total Cholesterol (mg/dL) & $122 \pm 6.44$ & $126 \pm 7.20$ & 1226.66 & 17 \\
\hline LDL (mg/dL) & $113 \pm 6.94$ & $119 \pm 8.93$ & $114 \pm 7.27$ & 15 \\
\hline HDL (mg/dL) & $38.1 \pm 1.96$ & $41.7 \pm 2.51$ & $43.7 \pm 2.57^{* *}$ & 12 \\
\hline
\end{tabular}

Values are expressed as mean concentration $\pm \mathrm{SEM} ;{ }^{*} p<0.05,{ }^{* * *} p<0.01$

\section{Discussion}

In this study, the relationship between ACE and inflammatory and lipid biomarkers that are associated with CVD before, at 30 min ACE and $2 \mathrm{~h}$ post-ACE was investigated. This is the first comprehensive study to measure 5 lipid biomarkers, 10 cytokines, and 9 acute phase proteins at multiple time points on the same individual allowing for the statistical power to detect within-person change. Significant increases in heart rate, self-reported shivering sensations, perceived discomfort, $\mathrm{VO}_{2}$ and EE occurred after 30 min ACE. IL-1 $\beta, \mathrm{HDL}$, and a-2-macroglobin significantly increased, while fold change analysis detected additional significant differences in IL-2, IL-4, IL-10, and serum amyloid $\mathrm{P}$ following ACE.

Predictively, self-reported shivering sensations, whole body oxygen consumption, and EE increased in response to ACE as previously reported [34]. Conflicting data exists on the effect of acute cold exposure on heart rate where cold-water immersion increases [35] and cold air exposure decreases [36] heart rate after 2 h ACE. In this study, heart rate significantly increased, but largely due to an increase in heart rate in females. Increased heart rate due to ACE in females as compared to males has previously been reported [36]. Additionally, the present study indicated sex differences in self-reported discomfort due to ACE, with females rating cold discomfort higher than males. Given that the participants in this study were exposed to cold water at $7^{\circ} \mathrm{C}$ during $\mathrm{ACE}$, which is within a range of water temperatures that are found to be cold enough to produce cold pain sensation [37], the findings are generally in agreement with past research reporting that women are more sensitive to pain stimuli compared to men [38]. Sex difference in long-term cold acute exposure is attributed largely to differences in body mass, fat mass, surface area, and hormones [34].

The changes in three out of the four cytokines post-ACE have been previously investigated in the literature $[17,39,40]$. IL-1 $\beta$ is a pro-inflammatory cytokine secreted by monocytes and its expression is highly associated with chronic inflammatory disease including CVD. Previously, no change in IL- $\beta$ due to ACE in a temperaturecontrolled room have been reported [17], while our study reported an increase at $30 \mathrm{~min}$ ACE with further increase at $2 \mathrm{~h}$ post ACE. IL-4 
is another pro-inflammatory cytokine that increased at $30 \mathrm{~min}$ ACE and $2 \mathrm{~h}$ post-ACE in the current study. IL-4 has been implicated in atherosclerosis development, although the exact mechanism in inflammatory processes related to CVD is unclear [21]. Increases in IL-4 have been reported in cold exposure greater than $3 \mathrm{~h}$ in animals $[19,22]$. It is unclear how increases in IL- $1 \beta$ and IL-4 play a role in disease risk in ACE, but the acute elevation indicates activation of the immune system in response to ACE. Conversely, IL-2 and IL-10, two cytokines that signal the resolution of inflammation and are involved in anti-inflammatory responses [22,23] increased $2 \mathrm{~h}$ post-ACE in our study. In agreement with our study, a previous study shows elevated IL-2 and IL-10 in response to ACE in a climate-controlled chamber with or without exercise [19]. Taken together, it appears that ACE triggers specific cytokine release, temporally modulating inflammatory and anti-inflammatory processes.

Immune differences in males and females are well documented and are dictated primarily by genes on the sex chromosome and hormones $[41,42]$. Typically, females have a stronger immune response to infection which correlates to increased survival and decreased susceptibility to infection than males [41]. In this study, males had an increased immune response due to ACE at $2 \mathrm{~h}$ for Il-2, IL-4, and IL-8 compared to baseline. Females had increased expression of these cytokines, but levels did not reach statistical significance. This may be due to fluctuations of cytokines during specific phases of the menstrual cycle [42], which was not accounted for in this study, or the small number of females.

Seven out of the nine acute phase proteins measured did not change in response to ACE. Significant increases in $\alpha$-2-macroglobulin and serum amyloid $\mathrm{P}$ were measured at $30 \mathrm{~min} \mathrm{ACE}$ but returned to pre-ACE after $2 \mathrm{~h}$ post-ACE. Both acute phase proteins have not been previously studied in response to ACE. Alpha-2-macroglobulin is a protein involved in humoral defense but has been investigated as a marker for CVD, but the data is conflicting [26,28]. Elevated serum amyloid P in blood is associated with increased angina and myocardial infarction [31] and may play a role in cardiac remodeling [27]. In summary, acute phase proteins remained unchanged or returned to pre-ACE values $2 \mathrm{~h}$ post-ACE. Based on these results, $\alpha$-2-macroglobulin, serum amyloid $\mathrm{P}$, and the seven other acute phase proteins may not have a large role in acute responses to ACE.

Sex differences of the acute phase proteins were found between ferritin, fibrinogen, CRP, and a-2-macroglobulin. Ferritin levels in females was lower than males at each time point, which is consistent with data showing menstruating females have lower levels of iron [43]. Surprisingly, the average ferritin values indicate below normal values of $12-150 \mathrm{ng} / \mathrm{mL}$ for females [44], indicating the female study population may be at risk for iron-deficiency anemia. Increases in $\alpha-2$ macroglobulin in males at $30 \mathrm{~min}$ ACE was likely due to the lower baseline values as compared to females, although both males and females increased at $30 \mathrm{~min} A C E$ and returned to baseline values at $2 \mathrm{~h}$ post ACE. Both fibrinogen after $30 \mathrm{~min} A C E$ and CRP at $2 \mathrm{~h}$ post ACE increased in females only. Elevations in acute phase proteins, fibrinogen [20] and CRP [25] among females indicates potential CVD risk due to ACE.

Dyslipidemia, characterized by elevated TC, LDL, TG, or NEFA and decreased HDL, is associated increased risk for CVD. Previous studies have documented an increase in plasma NEFA and TG in response to ACE to provide substrate for uncoupled oxidative phosphorylation (non-shivering thermogenesis) in brown adipose tissue. In this study, plasma NEFA and TG did not significantly increase in response to ACE.
The thermogenic effect of shivering likely prevented a large decrease tympanic temperature during this short-term exposure. The duration of ACE may be important as other studies reported increases of NEFA or TG after $\geq 90$ min cold exposure $[45,46]$ that may induce non-shivering thermogenesis. Interestingly, HDL incrementally increased by $8 \%$ with $30 \mathrm{~min} \mathrm{ACE}$ and an additional $8 \% 2 \mathrm{~h}$ post-ACE which is consistent with reported data in cold exposure in a temperature-controlled room for $60 \mathrm{~min}$ in humans [17] and $30 \mathrm{~min}$ in rats [46]. Taken together, these data suggest ACE may have a positive acute effect on HDL blood levels. Future studies are warranted to investigate whether frequent exposure of ACE could elevate HDL levels.

Sex differences in lipoprotein metabolism and plasma profiles are well documented [47]. Typically, premenopausal females have lower plasma TC, TG and LDL and higher HDL cholesterol levels than males. In this study, female HDL levels increased due to ACE and remained elevated at $2 \mathrm{~h}$. Surprisingly, LDL baseline values were higher in females than males but differences in TC, TG, FFA, and HDL were not found between males and females, likely due to the low power and high variation between individuals.

Limitations of this study include the homogenous population of convenience consisting of young, healthy adults, lack of core or skin temperature, lack of control group for venipuncture stress and non-cold controls, and females were not screened for stages of the menstrual cycle or oral contraception use. It is likely that ACE may result in different expression of these biomarkers depending on age, body mass, and disease status. For example, individuals with chronic inflammation and elevated levels of cytokines, acute phase proteins, and lipids may respond differently to ACE due to the fact their immune system is already activated, and lipid metabolism is altered. Supporting our assumption, we found that interferon gamma (INF- $\gamma$ ), one of pro-inflammatory cytokines, was undetectable in this healthy population (data not shown). Although this study lacks controls for cold exposure and venipuncture stress, each study participant is their own control at baseline that represents a "non-cold stressed" control and venipunctures were a constant stress and unlikely to affect differences reported from baseline, $30 \mathrm{~min}$ ACE, and $2 \mathrm{~h}$ post ACE. Core temperature can be assumed unchanged based on the small decreases in tympanic temperature but was not directly measured. Collecting skin temperatures was not possible with our study protocol due to continuous water pouring. Previous reports suggest tympanic and skin temperatures do not differ during 120 minutes of cold exposure and tympanic temperatures correlate with drops in skin temperature [48]. A drop in $1^{\circ} \mathrm{C}$ of tympanic temperature resulted in physiological responses to acute cold (elevation in TSH) [49]. Thus, tympanic temperatures can be used to detect physiologically relevant drops in temperature in response to acute cold that may mirror skin temperatures. Lastly, females respond differently to cold exposure when taking oral contraceptive and in different stages of the menstrual cycle [34] which was not accounted for in this study.

\section{Conclusions}

In conclusion, our results provide data on the effect of ACE on inflammation, the acute phase response, and lipid biomarkers. Acute cold exposure has the potential to induce pro-inflammatory cytokines associated with CVD (IL-1 $\beta$, IL-4), but also increased antiinflammatory cytokines (IL-2 and IL-10) which can dampen the inflammatory response. Increased HDL levels with increased EE and $\mathrm{VO} 2$ are the positive effects of ACE. However, ACE could give the negative impact on CVD, particularly seen in females (i.e., elevated 
levels of fibrinogen and CRP); thus, the long-term risk of CVD needs further exploration to assess the risks or benefits of ACE. Future studies with diverse subjects varying in age and body composition and studies aimed to determine the effectiveness of ACE as compared to diet and exercise are warranted.

\section{Compliance with Ethical Standards}

The authors declare that they have no conflict of interest.

All procedures performed in studies involving human participants were in accordance with the ethical standards of the institutional research committee and with the 1964 Helsinki declaration and its later amendments or comparable ethical standards. Informed consent was obtained from all individual participants included in the study.

\section{Acknowledgements}

We would like to thank the UTSA South Texas Center for Emerging Infectious Diseases for the use of the Bioplex analysis unit and Dr. Floyd Wormley for the use of his laboratory space. We appreciate Drs. Camaron Hole and Chrissy Wager for their technical expertise. We also would like to thank the UTSA undergraduate students who assisted in data collection and analysis.

\section{Funding}

This research did not receive any specific grant from funding agencies in the public, commercial, or not-for-profit sectors.

\section{References}

1. World Health Organization. The top 10 causes of death.

2. Centres for Disease Control and Prevention. Heart disease facts.

3. Vasan RS (2006) Biomarkers of Cardiovascular Disease: Molecular Basis and Practical Considerations. Circulation 113: 2335-2362. [Crossref]

4. Tucker JM, Welk GJ, Beyler NK (2011) Physical Activity in U.S. Adults. Am J Prev Med 40: 454-461. [Crossref]

5. Wilson MM, Reedy J, Krebs-Smith SM (2016) American Diet Quality: Where It Is, Where It Is Heading, and What It Could Be. J Acad Nutr Diet 116: 302-310.e1. [Crossref]

6. Ouellet V, Labbé SM, Blondin DP, Phoenix S, Guérin B, et al. (2012) Brown adipose tissue oxidative metabolism contributes to energy expenditure during acute cold exposure in humans. J Clin Invest 122: 545-552. [Crossref]

7. Ricci MR, Fried SK, Mittleman KD (2000) Acute cold exposure decreases plasma leptin in women. Metabolism 49: 421-423. [Crossref]

8. Hanna JN, McN Hill P, Sinclair JD (1975) Human cardiorespiratory responses to acute cold exposure. Clin Exp Pharmacol Physiol 2: 229-238. [Crossref]

9. Ohno H, Yahata T, Yamashita K, Kuroshima A (1987) Effect of acute cold exposure on ACTH and zinc concentrations in human plasma. Jpn J Physiol 37: 749-755. [Crossref]

10. Mercer JB, Osterud B, Tveita T (1999) The effect of short-term cold exposure on risk factors for cardiovascular disease. Thromb Res 95: 93-104. [Crossref]

11. Vigas M, Martino E, Bukovská M, Langer P (1988) Effect of acute cold exposure and insulin hypoglycemia on plasma thyrotropin levels by IRMA in healthy young males. Endocrinol Exp 22: 229-234. [Crossref]

12. Suzuki M, Tonoue T, Matsuzaki S, Yamamoto K (1967) Initial response of human thyroid, adrenal cortex, and adrenal medulla to acute cold exposure. Can J Physiol Pharmacol 45: 423-432. [Crossref]

13. Foxman EF, Storer JA, Fitzgerald ME, Wasik BR, Hou L, et al. (2015) Temperaturedependent innate defense against the common cold virus limits viral replication at warm temperature in mouse airway cells. Proc Natl Acad Sci U S A 112: 827-832. [Crossref]

14. Castellani JW, M Brenner IK, Rhind SG (2002) Cold exposure: human immune responses and intracellular cytokine expression. Med Sci Sports Exerc 34:2013-20. [Crossref]
15. Sun Z (2010) Cardiovascular responses to cold exposure. Front Biosci (Elite Ed) 2: 495-503. [Crossref]

16. Dong M, Yang X, Lim S, Cao Z, Honek J, et al. (2013) Cold Exposure Promotes Atherosclerotic Plaque Growth and Instability via UCP1-Dependent Lipolysis. Cell Metab 18: 118-129. [Crossref]

17. Guo JR, Li SZ, Fang HG, Zhang X, Wang JF, et al. (2012) Different Duration of Cold Stress Enhances Pro-Inflammatory Cytokines Profile and Alterations of Th1 and Th2 Type Cytokines Secretion in Serum of Wistar Rats. J Animal Vet Adv 11: 1538-1545.

18. Bartelt A, Bruns OT, Reimer R, Hohenberg H, Ittrich H, et al. (2011) Brown adipose tissue activity controls triglyceride clearance. Nat Med 17: 200-205. [Crossref]

19. Gagnon DD, Gagnon SS, Rintamäki H, Törmäkangas T, Puukka K, et al. (2014) The Effects of Cold Exposure on Leukocytes, Hormones and Cytokines during Acute Exercise in Humans. PLoS One 9: e110774. [Crossref]

20. Ford ES (2003) The metabolic syndrome and C-reactive protein, fibrinogen, and leukocyte count: findings from the Third National Health and Nutrition Examination Survey. Atherosclerosis 168: 351-358. [Crossref]

21. Lee YW, Hirani AA (2006) Role of interleukin-4 in atherosclerosis. Arch Pharm Res 29: 1-15. [Crossref]

22. Gaffen SL, Liu KD (2004) Overview of interleukin-2 function, production and clinical applications. Cytokine 28: 109-123. [Crossref]

23. Girndt M, Kohler H (2003) Interleukin-10 (IL-10): an update on its relevance for cardiovascular risk. Nephrol Dial Transplant 18: 1976-1979. [Crossref]

24. Kadoglou NPE, Biddulph JP, Rafnsson SB, Trivella M, Nihoyannopoulos P (2017) The association of ferritin with cardiovascular and all-cause mortality in communitydwellers: The English longitudinal study of ageing. PLoS One 12: e0178994. [Crossref]

25. Rutter MK, Meigs JB, Sullivan LM, D'Agostino RB Sr, Wilson PW (2004) C-Reactive Protein, the Metabolic Syndrome, and Prediction of Cardiovascular Events in the Framingham Offspring Study. Circulation 110: 380-385. [Crossref]

26. Tungtrongchitr R, Pongpaew P, Vudhivai N, Changbumrung S, Tungtrongchitr A, et al (2003) Relationship between alpha-2-macroglobulin, anthropometric parameters and lipid profiles in Thai overweight and obese in Bangkok. Nutrit Res 23: 1143-1152

27. Jenny NS, Arnold AM, Kuller LH, Tracy RP, Psaty BM (2007) Serum Amyloid P and Cardiovascular Disease in Older Men and Women: Results from the Cardiovascular Health Study. Arterioscler Thromb Vasc Biol 27: 352-358. [Crossref]

28. Swiatkowska-Stodulska R, Babińska A, Skibowska-Bielińska A, Sworczak K (2008) Assessment of alpha 1-antitrypsin and alpha2-macroglobulin levels in obese patients. Pol Arch Med Wewn 118: 713-718. [Crossref]

29. Schiopu A, Hedblad B, Engström G, Struck J, Morgenthaler NG, et al. (2012) Plasma procalcitonin and the risk of cardiovascular events and death: a prospective populationbased study. J Intern Med 272: 484-491. [Crossref]

30. Thompson JC, Jayne C, Thompson J, Wilson PG, Yoder MH, et al. (2015) A brief elevation of serum amyloid A is sufficient to increase atherosclerosis. J Lipid Res 56: 286-293. [Crossref]

31. Lee CW, Cheng TM, Lin CP, Pan JP (2013) Plasma Haptoglobin Concentrations Are Elevated in Patients with Coronary Artery Disease. PLoS One 8: e76817. [Crossref]

32. Horgan SJ, Watson CJ, Glezeva N, Collier P, Neary R, et al. (2015) Serum Amyloid P-Component Prevents Cardiac Remodeling in Hypertensive Heart Disease. $J$ Cardiovasc Transl Res 8: 554-566. [Crossref]

33. Cohen J (1992) A power primer. Psychol Bull 112: 155-159. [Crossref]

34. Castellani JW, Young AJ (2016) Human physiological responses to cold exposure Acute responses and acclimatization to prolonged exposure. Auton Neurosci 196: 63 74. [Crossref]

35. Solianik R, Skurvydas A, Vitkauskienè A, Brazaitis M (2014) Gender-specific cold responses induce a similar body-cooling rate but different neuroendocrine and immune responses. Cryobiology 69:26-33. [Crossref]

36. Wagner JA, Horvath SM (1985) Influences of age and gender on human thermoregulatory responses to cold exposures. J Appl Physiol 58: 180-186. [Crossref]

37. Van Ryckeghem DML, Van Damme S, Vervoort T (2018) Does attention bias modification training impact on task performance in the context of pain: An experimental study in healthy participants. PLoS One 13: e0200629. [Crossref]

38. Fillingim RB, King CD, Ribeiro-Dasilva MC, Rahim-Williams B, Riley JL $3^{\text {rd }}(2009)$ Sex, gender, and pain: a review of recent clinical and experimental findings. $J$ Pain 10 : 447-485. [Crossref] 
39. Hangalapura BN, Kaiser MG, Poel JJ, Parmentier HK, Lamont SJ (2006) Cold stress equally enhances in vivo pro-inflammatory cytokine gene expression in chicken lines divergently selected for antibody responses. Dev Comp Immunol 30: 503-511. [Crossref]

40. Leppäluoto J, Westerlund T, Huttunen P, Oksa J, Smolander J, et al. (2008) Effects of long-term whole-body cold exposures on plasma concentrations of ACTH, betaendorphin, cortisol, catecholamines and cytokines in healthy females. Scand J Clin Lab Invest 68: 145-153. [Crossref]

41. Klein SL, Flanagan KL (2016) Sex differences in immune responses. Nat Rev Immunol 16: 626-638. [Crossref]

42. Bouman A, Heineman MJ, Faas MM (2005) Sex hormones and the immune response in humans. Hum Reprod Update 11: 411-423. [Crossref]

43. Rushton DH, Barth JH (2010) What is the evidence for gender differences in ferritin and haemoglobin? Crit Rev Oncol Hematol 73: 1-9. [Crossref]

44. MedlinePlus (2016) Ferritin blood test. U.S. National Library of Medicine.
45. Hong JH, Kim HJ, Kim KJ, Suzuki K, Lee IS (2008) Comparison of metabolic substrates between exercise and cold exposure in skaters. J Physiol Anthropol 27: 273281. [Crossref]

46. Kozyreva TV, Lomakina SV, Tuzikov FV, Tuzikova NA (2004) Plasma lipoproteins under the effect of cold exposure in normotensive and hypertensive rats. J Therm Biol 29: $67-72$.

47. Wang X, Magkos F, Mittendorfer B (2011) Sex Differences in Lipid and Lipoprotein Metabolism: It's Not Just about Sex Hormones. J Clin Endocrinol Metab 96: 885-893. [Crossref]

48. Livingstone SD, Grayson J, Frim J, Allen CL, Limmer RE (1983) Effect of cold exposure on various sites of core temperature measurements. J Appl Physiol Respir Environ Exerc Physiol 54: 1025-1031. [Crossref]

49. Leppäluoto J, Pääkkönen T, Korhonen I, Hassi J (2005) Pituitary and autonomic responses to cold exposures in man. Acta Physiol Scand 184: 255-264. [Crossref]

Copyright: $(02018$ Ullevig SL. This is an open-access article distributed under the terms of the Creative Commons Attribution License, which permits unrestricted use, distribution, and reproduction in any medium, provided the original author and source are credited. 